\title{
Article \\ Cyanogel-Derived Synthesis of Porous PdFe Nanohydrangeas as Electrocatalysts for Oxygen Reduction Reaction
}

\author{
Jinxin Wan ${ }^{1, \dagger}$, Zhenyuan Liu ${ }^{1, *,+} \mathbb{C}$, Xiaoyu Yang ${ }^{2, \dagger}$, Peng Cheng ${ }^{1}$ and Chao Yan ${ }^{1, * \mathbb{D}}$ \\ 1 School of Materials Science and Engineering, Jiangsu University of Science and Technology, \\ Zhenjiang 212100, China; wjx192060036@163.com (J.W.); 15851702806@163.com (P.C.) \\ 2 State Key Laboratory for Artificial Microstructure and Mesoscopic Physics, School of Physics, \\ Peking University, Beijing 100871, China; yangxy1302@163.com \\ * Correspondence: zhenyuanliu@just.edu.cn (Z.L.); chaoyan@just.edu.cn (C.Y.) \\ + These authors contributed equally to this paper.
}

check for updates

Citation: Wan, J.; Liu, Z.; Yang, X.; Cheng, P.; Yan, C. Cyanogel-Derived Synthesis of Porous PdFe Nanohydrangeas as Electrocatalysts for Oxygen Reduction Reaction. Nanomaterials 2021, 11, 3382. https:// doi.org/10.3390/nano11123382

Academic Editor: Adriano Sacco

Received: 9 November 2021

Accepted: 10 December 2021

Published: 13 December 2021

Publisher's Note: MDPI stays neutral with regard to jurisdictional claims in published maps and institutional affiliations.

Copyright: (c) 2021 by the authors. Licensee MDPI, Basel, Switzerland. This article is an open access article distributed under the terms and conditions of the Creative Commons Attribution (CC BY) license (https:/ / creativecommons.org/licenses/by/ $4.0 /)$.

\begin{abstract}
It is important to develop cost-efficient electrocatalysts used in the oxygen reduction reaction (ORR) for widespread applications in fuel cells. Palladium (Pd) is a promising catalyst, due to its more abundant reserves and lower price than platinum $(\mathrm{Pt})$, and doping an earth-abundant 3d-transition metal M into Pd to form Pd-M bimetallic alloys may not only further reduce the use of expensive Pd but also promote the electrocatalytic performance of ORR, owing to the synergistic effect between $\mathrm{Pd}$ and M. Here we report a cyanogel-derived synthesis of PdFe alloys with porous nanostructure via a simple coinstantaneous reduction reaction by using $\mathrm{K}_{2} \mathrm{Pd}^{\mathrm{II}} \mathrm{Cl}_{4} / \mathrm{K}_{4} \mathrm{Fe}^{\mathrm{II}}(\mathrm{CN})_{6}$ cyanogel as precursor. The synthesized PdFe alloys possess hydrangea-like morphology and porous nanostructure, which are beneficial to the electrochemical performance in ORR. The onset potential of the porous PdFe nanohydrangeas is determined to be $0.988 \mathrm{~V}$, which is much more positive than that of commercial Pt/C catalyst $(0.976 \mathrm{~V})$ and Pd black catalyst $(0.964 \mathrm{~V})$. Resulting from the unique structural advantages and synergetic effect between bimetals, the synthesized PdFe nanohydrangeas with porous structure have outstanding electrocatalytic activity and stability for ORR, compared with the commercial Pd black and $\mathrm{Pt} / \mathrm{C}$.
\end{abstract}

Keywords: PdFe alloy; cyanogel; porous nanohydrangeas; oxygen reduction reaction; fuel cells

\section{Introduction}

Proton exchange membrane fuel cells (PEMFCs) have aroused increasing attention as one of the most promising renewable energy conversion systems on account of their high energy conversion efficiency, low operation temperature, and environmentally benign products [1-3]. As a crucial cathode reaction in PEMFCs, the oxygen reduction reaction (ORR) has attracted enormous research interest [4-9]. However, the overall efficiency of energy conversion is limited due to the intricate reaction process and inherently sluggish reaction kinetics of ORR. Generally, platinum $(\mathrm{Pt})$ and Pt-based alloys have been deemed to be the most effective electrocatalysts for ORR [10-12]. Nevertheless, some decisive issues, including scarce reserve, high price, poor durability, and fuel crossover, hampered their large-scale commercialization for PEMFCs. In this connection, it is highly important to develop alternative Pt-free electrocatalysts with prominent catalytic properties in ORR. Palladium (Pd), in the same family as $\mathrm{Pt}$, is more abundant and less expensive and has similar structure and properties to $\mathrm{Pt}$ and better electrocatalytic performance than $\mathrm{Pt}$-based catalysts. Moreover, doping an earth-abundant $3 d$-transition metal $\mathrm{M}(\mathrm{M}=\mathrm{Ni}, \mathrm{Co}, \mathrm{Cu}$, $\mathrm{Fe}$, etc.) into Pd to form Pd-M bimetallic alloys can not only further reduce the use of expensive Pd but also tune the electronic structure of Pd effectively, which always results in excellent electrocatalytic performance [13-16]. For instance, Bharali's group prepared carbon-supported PdNi electrocatalysts, which have remarkable ORR and formic acid oxidation behavior [17]. Cheng's group demonstrated that one-dimensional $\mathrm{PdCu}$ 
nanocrystals prepared via a seed-mediated approach exhibited better performance for ORR [18]. Among varieties of $3 d$-transition metals, Fe has been recognized as a promising element to constitute $\mathrm{Pd}-\mathrm{Fe}$ alloys because of its relatively low cost and elaborate synergistic effect [19-21]. The doping of Fe into a Pd lattice would shorten the interatomic distance of $\mathrm{Pd}-\mathrm{Pd}$ and lead to compressive strain, which can quite improve the electrocatalytic activity of ORR by boosting the valid adsorption of active oxygen. What is more, because of the different electronegativities, the changing of the electronic structure for Pd with Fe results in the downshift of the Pd $d$-band center, which can efficiently reduce the adsorption of oxygenated species on the catalysts' surface and increase the active sites. Therefore, PdFe nanoalloys are deemed to be greatly economical and efficient ORR electrocatalysts.

In addition, morphology control is another efficient method to affect the catalysts' electrochemical properties. Porous nanostructures can enhance the atoms' utilization efficiency of noble metals and possess a much larger surface area, providing abundant active sites, which can improve the activity [22-24]. What is more, the porous nanostructures not only can facilitate mass diffusion and transport but also hinder the dissolution and agglomeration of nanocatalysts. Hence, enormous efforts have been made to develop synthetic approaches to prepare Pd-based nanocatalysts with porous structures, including self-assembly [25], electrodeposition [26,27], hard template-engaged method [28,29], and so on. Despite these advances, those previously reported synthetic strategies are tedious and complex, dramatically impeding the large-scale practical applications of these nanomaterials in energy-related fields. Thus, it is greatly fulfilling to design a gentle and economical method for the preparation of Pd-based alloys with porous structure. Cyanogel is a category of coordinate polymer made from the reaction of a tetrachlorometalate $\left(\left[\mathrm{RCl}_{4}\right]^{2-}\right.$, $\mathrm{R}=\mathrm{Pt}, \mathrm{Pd}, \mathrm{Ir})$ and a transition metal cyanometalate $\left(\left[\mathrm{M}(\mathrm{CN})_{\mathrm{n}}\right]^{2-/ 3-}, n=4,6 ; \mathrm{M}=\mathrm{Fe}\right.$, $\mathrm{Co}, \mathrm{Ni}$ in aqueous solution, as shown in Equation S1 (Supplementary Materials) [30-33]. Therefore, cyanogels can be used as various multi-metal precursors for the fabrication of bimetallic nanoalloys, avoiding the risk of alloy multiphases and complicated processes which frequently occur in the traditional reduction methods.

Herein, we demonstrate a simple preparation of PdFe nanohydrangeas with porous structure (PdFe PNHs) through a cyanogel-derived method at room temperature. The PdFe PNHs were obtained by using $\mathrm{K}_{2} \mathrm{Pd}^{\mathrm{II}} \mathrm{Cl}_{4} / \mathrm{K}_{4} \mathrm{Fe}^{\mathrm{II}}(\mathrm{CN})_{6}$ cyanogel as precursor and hydrazine hydrate $\left(\mathrm{N}_{2} \mathrm{H}_{4} \cdot \mathrm{H}_{2} \mathrm{O}\right)$ as reduction agent. Because of their hydrangea-like porous morphology and alloy nanostructure, the prepared PdFe PNHs have a high density of active sites. The electrochemically active surface area (ECSA) of the PdFe PNHs is 2.1 times larger than that of the commercial Pd black. Thus, the prepared PdFe PNHs exhibit enhanced electrochemical activity and durability for ORR in alkaline medium. Our strategy is simple, environmentally friendly, and will contribute to the further design of bimetallic alloys.

\section{Materials and Methods}

\subsection{Reagents}

Potassium tetrachloropalladite(II) $\left(\mathrm{K}_{2} \mathrm{PdCl}_{4}\right)$, potassium hexacyanoferrate(II) $\left(\mathrm{K}_{4} \mathrm{Fe}(\mathrm{CN})_{6}\right)$, and hydrazine hydrate $\left(\mathrm{N}_{2} \mathrm{H}_{4} \cdot \mathrm{H}_{2} \mathrm{O}, 50 \%\right)$ were obtained from Sinopharm Chemical Reagent Co., Ltd. (Shanghai, China). Commercial Pd black and Pt/C were bought from Johnson Matthey Corporation. All chemicals and reagents were used without further purification. All of the aqueous solutions were prepared using Millipore water with a resistivity of $18.2 \mathrm{M} \Omega$.

\subsection{Synthesis of PdFe Porous Nanohydrangeas}

In a typical synthesis, $6 \mathrm{~mL}$ of $50 \mathrm{mM} \mathrm{K}_{2} \mathrm{PdCl}_{4}$ and $3 \mathrm{~mL}$ of $50 \mathrm{mM} \mathrm{K}_{4} \mathrm{Fe}(\mathrm{CN})_{6}$ aqueous solutions were initially mixed at room temperature. After $5 \mathrm{~min}$, the orange-red $\mathrm{Pd}-\mathrm{Fe}$ cyanogel was formed. Then, $6 \mathrm{~mL}$ of diluted $\mathrm{N}_{2} \mathrm{H}_{4} \cdot \mathrm{H}_{2} \mathrm{O}$ solution (containing $3 \mathrm{~mL}$ $\mathrm{N}_{2} \mathrm{H}_{4} \cdot \mathrm{H}_{2} \mathrm{O}, 50 \%$ ) was added into the Pd-Fe cyanogel slowly, and the resulting mixture was left to stand for an additional $36 \mathrm{~h}$. After reaction, the black PdFe porous nanohydrangeas were separated by centrifugation at $15,000 \mathrm{rpm}$ for $5 \mathrm{~min}$, washed several times with water and $\mathrm{NaOH}$ solution, and then dried at $40^{\circ} \mathrm{C}$ for $12 \mathrm{~h}$ in a vacuum oven. 


\subsection{Characterizations}

The morphology and structure of products were measured with a Hitachi S-4800 scanning electron microscope (SEM) and JEOL JEM-2010 transmission electron microscope (TEM). High-resolution TEM (HRTEM), energy-dispersive X-ray (EDX), high-angle annular dark-field scanning transmission electron microscopy (HAADF-STEM), and elemental mapping measurements were carried out on a FEI Tecnai G2 F20 microscope, which was built as an accessory on the JEOL JEM-2100F. The Fourier transform infrared (FTIR) spectra were obtained with a Nicolet 520 SXFTIR spectrometer. The Brunauer-Emmett-Teller (BET) specific surface area and pore size distribution were examined at $77 \mathrm{~K}$ using a Micromeritics ASAP 2050 system. The phase purity and crystallinity of the products were confirmed by X-ray diffraction (XRD) on a Model D/max-rC X-ray diffractometer using $\mathrm{Cu} \mathrm{K} \alpha$ radiation source $(\lambda=1.5406 \AA)$ and operating at $40 \mathrm{kV}$ and $100 \mathrm{~mA}$. X-ray photoelectron spectroscopy (XPS) tests were performed on a Thermo VG Scientific ESCALAB 250 spectrometer with a monochromatic $\mathrm{Al} \mathrm{K} \alpha \mathrm{X}$-ray source $(1486.6 \mathrm{eV}$ photons). The binding energy was trued with respect to $\mathrm{C} 1 \mathrm{~s}$ at $284.6 \mathrm{eV}$.

\subsection{Electrochemical Measurements}

All electrochemical experiments were performed on a CHI $760 \mathrm{D}$ electrochemical workstation ( $\mathrm{CH}$ Instruments, Chenhua Co., Shanghai, China,) at $25{ }^{\circ} \mathrm{C}$. A standard three-electrode system was used for all electrochemical experiments which was made up of a platinum foil as the auxiliary electrode, a saturated calomel reference electrode as the reference electrode, and a RRDE modified with catalysts as the working electrode. Potentials in this work were recorded with respect to the reversible hydrogen electrode (RHE). The catalyst suspension was prepared by dispersing $5 \mathrm{mg}$ of catalyst in $1 \mathrm{~mL}$ of solution containing $0.9 \mathrm{~mL}$ of deionized (DI) water and $0.1 \mathrm{~mL}$ of $0.5 \mathrm{wt} \%$ Nafion solution, followed by ultrasonication for $30 \mathrm{~min}$. For the immobilization of catalyst, $10 \mu \mathrm{L}$ of the catalyst suspension was dropped onto the RRDE surface $\left(0.196 \mathrm{~cm}^{2}\right)$ and then dried at ambient temperature. Cyclic voltammetry $(\mathrm{CV})$ was performed in a $\mathrm{N}_{2}$-saturated $0.5 \mathrm{M}$ $\mathrm{H}_{2} \mathrm{SO}_{4}$ solution. The ECSA of the catalysts could be calculated using the following equation: ECSA $=Q /(m C)$, where $m$ is the loading amount of Pd and the ECSA is calculated by integrating the charges $(Q)$ associated with the peak from the reduction of Pd oxide, assuming $420 \mu \mathrm{C} \mathrm{cm}^{-2}$ is needed for the reduction of a Pd oxide monolayer. The ORR tests were carried out in an $\mathrm{O}_{2}$-saturated $0.1 \mathrm{M} \mathrm{KOH}$ solution with a sweep rate of $5 \mathrm{mV} \mathrm{s}^{-1}$ and a rotation rate of $1600 \mathrm{rpm}$. The electron transfer number $(n)$ is calculated based on the equation of $n=4 I_{\mathrm{d}} /\left(I_{\mathrm{d}}+\left(I_{\mathrm{r}} / N\right)\right)$, where $I_{\mathrm{d}}$ and $I_{\mathrm{r}}$ stand for the disk current and ring current, respectively, and $N$ is the current collection efficiency of the Pt ring (0.37).

\section{Results and Discussion}

The overall synthesis process of PdFe nanohydrangeas is schematically shown in Figure 1. The orange-red PdFe cyanogels with three-dimensional (3D) network structure were achieved by mixing $\mathrm{K}_{2} \mathrm{PdCl}_{4}$ and $\mathrm{K}_{4} \mathrm{Fe}(\mathrm{CN})_{6}$ aqueous solutions (Figure S1). During the gelation process, the nitrogen end of the cyanide ligands in $\mathrm{K}_{4} \mathrm{Fe}(\mathrm{CN})_{6}$ could replace transchloride ligands in $\mathrm{K}_{2} \mathrm{PdCl}_{4}$. The characteristic stretching peak of $\mathrm{C} \equiv \mathrm{N}$ has a positive shift relative to that of $\mathrm{K}_{4} \mathrm{Fe}(\mathrm{CN})_{6}$ in the FTIR spectrum (Figure S2), which validates the successful formation of PdFe cyanogels. After addition of $\mathrm{N}_{2} \mathrm{H}_{4} \cdot \mathrm{H}_{2} \mathrm{O}$ to the cyanogels, the porous PdFe nanohydrangeas (PdFe PNHs) were obtained by centrifugation and washing. 


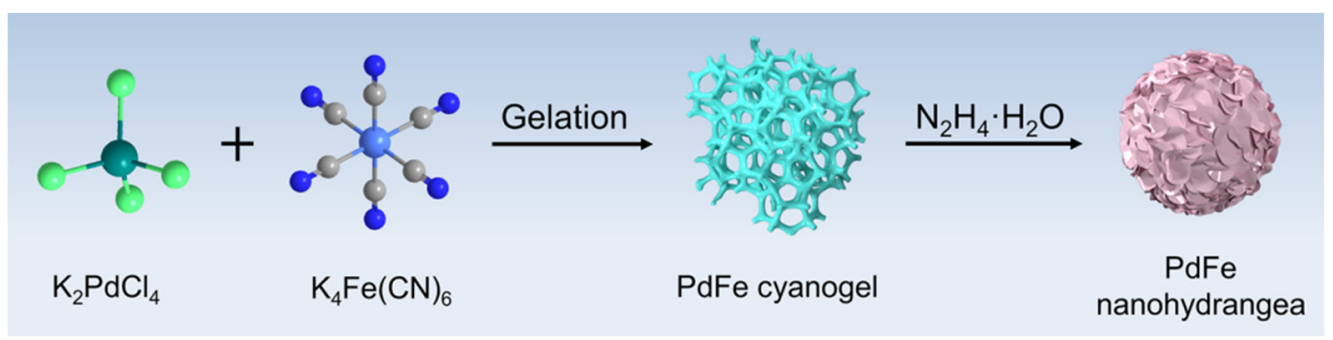

Figure 1. Schematic illustration of the formation of porous PdFe nanohydrangeas.

The morphology and nanostructure of the PdFe PNHs were characterized with SEM, HAADF-STEM, and TEM. As viewed from SEM images (Figure S3) and the HAADF-STEM image (Figure 2a), the PdFe PNHs exhibit a porous, hydrangea-like structure. Consistent with the SEM and HAADF-STEM observation, the TEM image further confirms the porous, hydrangea-like nanostructure composed of interconnected small nanoparticles (Figure 2b). $\mathrm{N}_{2}$ adsorption-desorption isotherms of the PdFe PNHs display a distinctive hysteresis loop corresponding to type IV behavior (Figure 2c), suggesting that the porous structures are existent. Calculated from the $\mathrm{N}_{2}$ isotherms, the BET surface area is around $92 \mathrm{~m}^{2} \mathrm{~g}^{-1}$. The abundant pores and large surface area of the PdFe PNHs can facilitate transportation and infiltration of the reaction substances, offering more active surface sites, which benefit electrocatalytic reactions. The HRTEM image (Figure $2 \mathrm{~d}$ ) and the corresponding SAED pattern (Figure 2e) suggest that the PdFe PNHs consist of multiple coalesced crystalline segments with a face-centered cubic $(f c c)$ polycrystalline structure. As marked in Figure $2 f$, the lattice plane with an interplanar distance of $0.222 \mathrm{~nm}$ is vested in the (111) plane in $f c c$-phased PdFe alloy. Furthermore, distortions and nanotwins can also be observed in the HRTEM images (Figure $2 \mathrm{~g}$,h); these can be used as active sites for electrocatalysis. Elemental mapping analysis discloses that $\mathrm{Pd}$ and Fe are distributed uniformly throughout the nanohydrangeas entirely, proving the formation of PdFe alloys (Figure 2i). This conclusion is further proved by the corresponding EDX line-scanning analysis (Figure S4), where Pd and Fe signals appear incidentally during the line-scanning process.

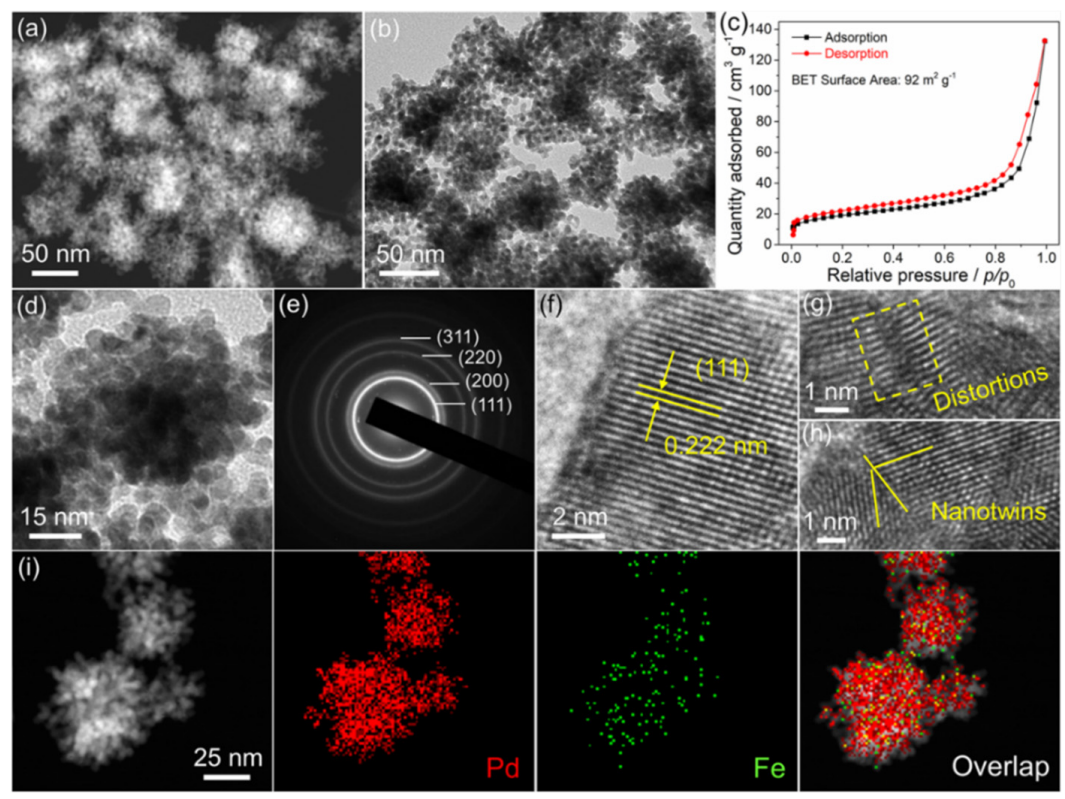

Figure 2. Morphological characterizations of the porous PdFe nanohydrangeas. (a) HAADF-STEM image; (b) TEM image; (c) $\mathrm{N}_{2}$ adsorption-desorption isotherms; (d) HRTEM; (e) SAED pattern; (f-h) magnified HRTEM images; (i) HAADF-STEM image and elemental mapping images. 
Figure $3 \mathrm{a}$ is the XRD pattern of the fabricated PdFe nanohydrangeas, which can be indexed to $f c c$-phased metal. In particular, all diffraction peaks are positioned between the standard peaks of pure Pd and $\mathrm{Fe}$, proving the formation of PdFe alloys. As displayed in Figure 3b, the EDX spectrum implies the existence of $\mathrm{Pd}$ and Fe with a Pd/Fe molar ratio of 86.4:13.6 in the PdFe nanohydrangeas. As identified by XPS analysis (Figure S5), the Pd/Fe atomic ratio on the surface of the PdFe nanohydrangeas is 89.7:10.3, nearly identical to the data estimated by EDX. This result further demonstrates that $\mathrm{Pd}$ and Fe are homogeneously distributed throughout the PdFe nanohydrangeas. As exhibited in Figure 3c, the peaks located at 335.5 and $340.8 \mathrm{eV}$ are vested in the metallic state of Pd in the PdFe catalysts, while the peaks at 336.5 and $341.9 \mathrm{eV}$ are the oxidized species. The percentage of $\mathrm{Pd}^{0}$ species is approximately $84.9 \%$, implying that Pd exists predominantly in a zero-valent state in the PdFe nanohydrangeas. Figure $3 \mathrm{~d}$ is the high-resolution Fe $2 p$ spectrum of the PdFe nanohydrangeas. According to previous reports [34-36], the peaks at 711.2 and $716.5 \mathrm{eV}$ belong to the binding energies of $2 \mathrm{p}_{3 / 2}$ bands of $\mathrm{Fe}^{2+}$ and $\mathrm{Fe}^{3+}$ species, respectively. Meanwhile, the peaks at 725.3 and $729.7 \mathrm{eV}$ are attributed to the binding energy of $2 \mathrm{p}_{1 / 2}$ orbitals of $\mathrm{Fe}^{2+}$ and $\mathrm{Fe}^{3+}$ species. The peak at $720.7 \mathrm{eV}$ is a satellite peak for the above four peaks, indicating the coexistence of $\mathrm{Fe}^{2+}$ and $\mathrm{Fe}^{3+}$ in the catalyst.
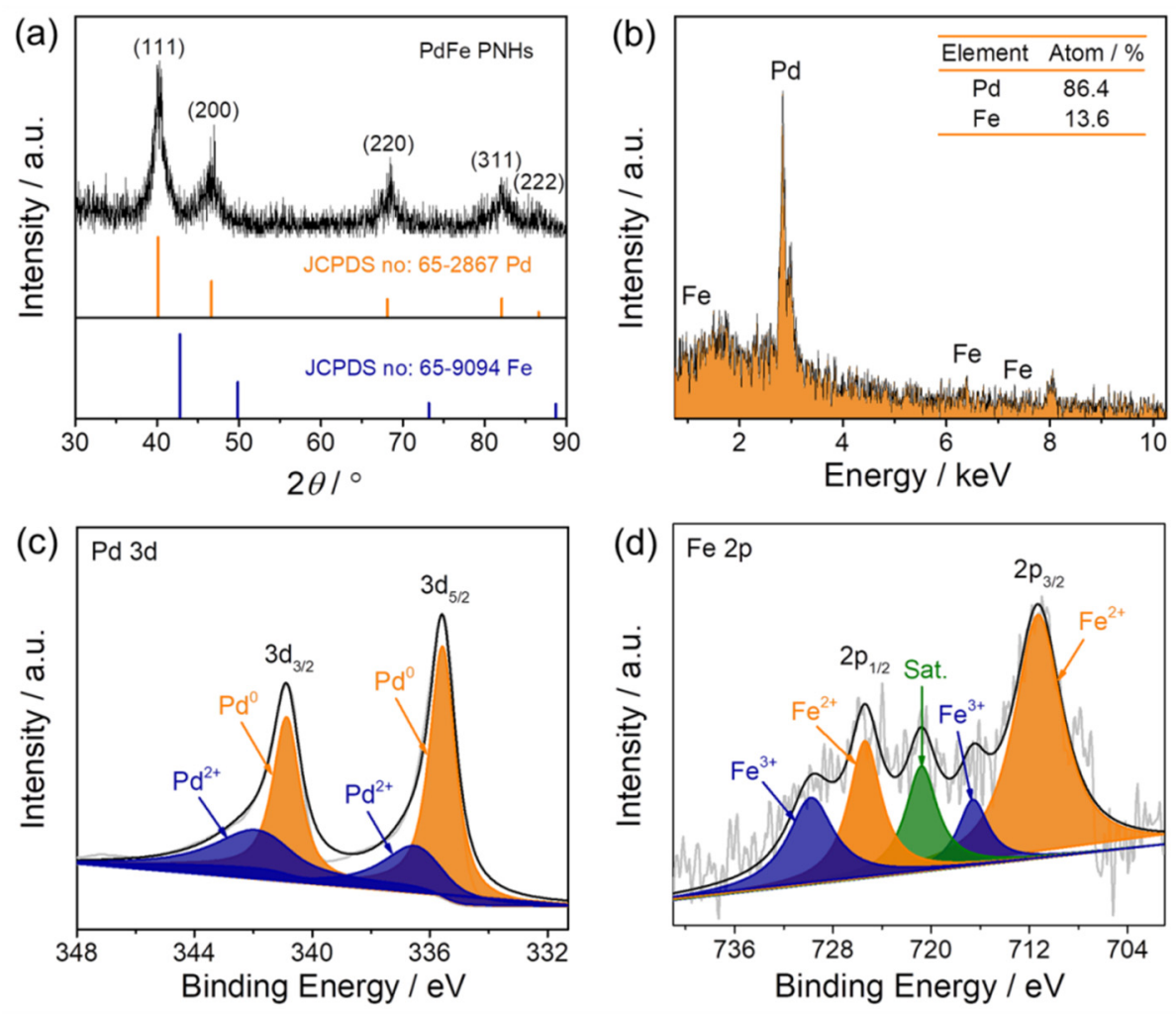

Figure 3. Compositional analyses of the porous PdFe nanohydrangeas. (a) XRD pattern; (b) EDX spectrum; (c) high-resolution Pd 3d XPS spectrum; (d) high-resolution Fe 2p XPS spectrum.

In consideration of the picturesque porous, hydrangea-like morphology and alloy nanostructure, the synthesized PdFe PNHs are supposed to have excellent electrocatalytic performance. Accordingly, the electrocatalytic properties of the porous PdFe nanohydrangeas for ORR were measured in alkaline medium to emphasize their structural and compositional advantages. For comparison, commercial Pd black and $\mathrm{Pt} / \mathrm{C}$ catalysts were also appraised under the same experimental conditions. Figure S6a shows the representative $\mathrm{CV}$ curves of the two electrocatalysts in the $\mathrm{N}_{2}$-saturated $0.5 \mathrm{M} \mathrm{H}_{2} \mathrm{SO}_{4}$ solution. According to the integrated charges for the reduction of $\mathrm{PdO}$ monolayer during the cathodic scan $[37,38]$, the ECSA of the porous PdFe nanohydrangeas is calculated to be $15.5 \mathrm{~m}^{2} \mathrm{~g}^{-1}$, while that of the commercial Pd black is $7.4 \mathrm{~m}^{2} \mathrm{~g}^{-1}$. The prominent enhancement of the 
ECSA of the PdFe PNHs may result from its porous characteristics, with large surface area. Firstly, we tested the ORR performance of the three catalysts in $\mathrm{O}_{2}$-saturated $0.1 \mathrm{M} \mathrm{KOH}$ solution with a sweep rate of $5 \mathrm{mV} \mathrm{s}^{-1}$ and a rotation rate of $1600 \mathrm{rpm}$. Figure $4 \mathrm{a}$ shows the typical ORR polarization curves of the three catalysts. As summarized in Figure $4 b$, the onset potential $\left(E_{0}\right)$ and half-wave potential $\left(E_{1 / 2}\right)$ of the porous PdFe nanohydrangeas are determined to be 0.988 and $0.861 \mathrm{~V}$, respectively, which are much more positive than those of commercial $\mathrm{Pt} / \mathrm{C}$ catalyst $(0.976$ and $0.858 \mathrm{~V})$ and Pd black catalyst (0.964 and $0.844 \mathrm{~V}$ ) and able to be compared with those of the reported electrocatalysts (Table S1). Figure $4 \mathrm{c}$ shows the corresponding Tafel plots of the kinetic current density $\left(j_{\mathrm{k}}\right)$ computed from the ORR polarization curves. Notably, the $j_{\mathrm{k}}$ value of the PdFe PNHs is the highest at the same applied potential, indicating that the PdFe PNHs possess better kinetic behavior than commercial Pd black and $\mathrm{Pt} / \mathrm{C}$ catalysts. Together with the more positive $E_{0}$ and $E_{1 / 2}$ data, these consequences forcefully show that the porous PdFe nanohydrangeas exceed the reference catalysts with respect to ORR. To further study the ORR mechanism of the porous PdFe nanohydrangeas, we used RRDE tests to trace the production yield of hyperoxide species $\left(\mathrm{HO}_{2}^{-}\right)$during the ORR process (Figure 4d). Figure 4e suggests that the peroxide yield is quite low $(<5 \%)$ for the PdFe PNHs during ORR. The number of electron transfers $(n)$ is calculated to be $3.95-3.99$ at the potential of $0.2-0.8 \mathrm{~V}$, revealing that the ORR process is a four-electron pathway. Moreover, the electron transfer number can also be calculated from the Koutecky-Levich (K-L) plots. Figure S7 displays the ORR polarization curves of the three catalysts obtained in $\mathrm{O}_{2}$-saturated $0.1 \mathrm{M} \mathrm{KOH}$ solution with a sweep rate of 5 $\mathrm{mV} \mathrm{s}^{-1}$ and different rotation speeds, as well as the relevant $\mathrm{K}-\mathrm{L}$ plots. As expected, the PdFe PNHs shows a high electron transfer number (3.96) which is comparable to those of commercial Pt/C (3.92) and Pd black (3.89) catalysts.
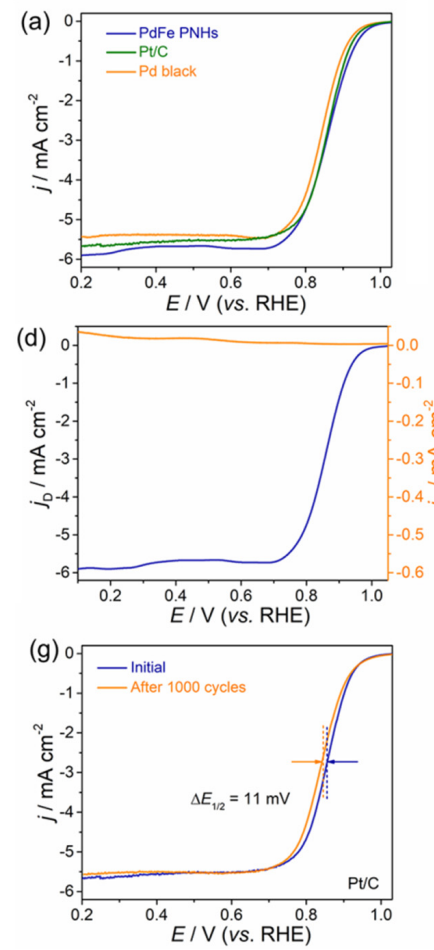
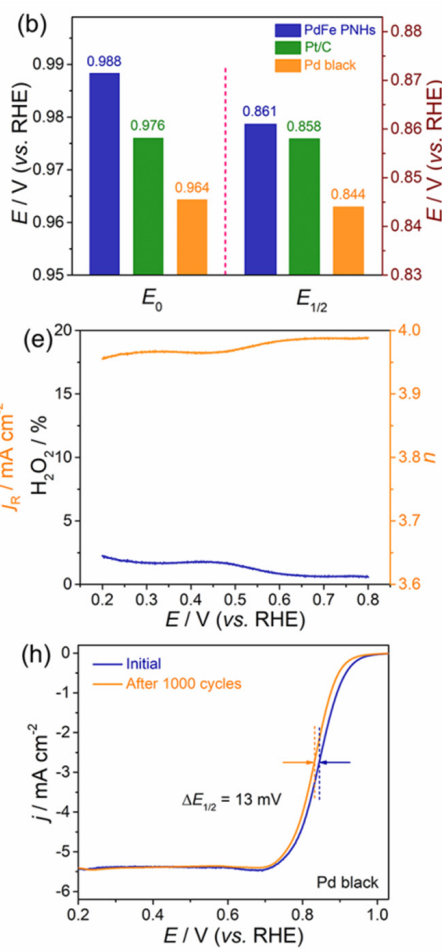
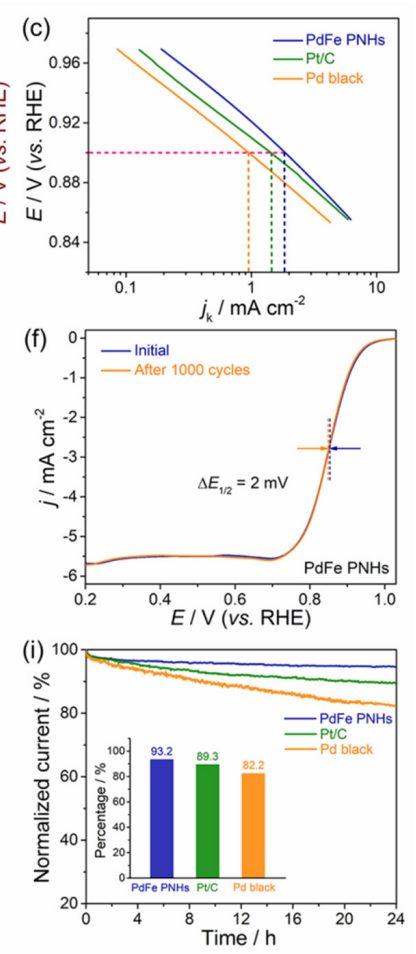

Figure 4. ORR performances of the porous PdFe nanohydrangeas, commercial Pd black, and Pt/C. (a) ORR polarization curves obtained in an $\mathrm{O}_{2}$-saturated $0.1 \mathrm{M} \mathrm{KOH}$ solution with a sweep rate of $5 \mathrm{mV} \mathrm{s}^{-1}$ and a rotation rate of $1600 \mathrm{rpm}$; (b) comparison of $E_{0}$ and $E_{1 / 2}$ for the three catalysts; (c) Tafel plots; (d) currents gathered on disk and ring electrodes catalyzed by the porous PdFe nanohydrangeas; (e) $\mathrm{H}_{2} \mathrm{O}_{2}$ yield and electron transfer number of the porous PdFe nanohydrangeas in ORR; (f) ORR polarization curves of the porous PdFe nanohydrangeas before and after 1000 cycles; (g) ORR polarization curves of the commercial $\mathrm{Pt} / \mathrm{C}$ before and after 1000 cycles; (h) ORR polarization curves of the commercial Pd black before and after 1000 cycles; (i) CA tests of the three catalysts in $\mathrm{O}_{2}$-saturated $0.1 \mathrm{M} \mathrm{KOH}$. 
In addition, long-term stability is also a significant aspect of electrocatalysts to evaluate electrocatalytic performance. Accelerated durability tests (ADTs) for 1000 cycles were carried out to evaluate the ORR durability of the three catalysts (Figure $4 \mathrm{f}-\mathrm{h}$ ). The half-wave potential of the PdFe PNHs exhibits an unspectacular degradation with just $2 \mathrm{mV}$ negative shift, which is much lower than the commercial Pt/C $(11 \mathrm{mV})$ and Pd black $(13 \mathrm{mV})$. Furthermore, the stability of the three catalysts was also tested by chronoamperometry (CA) measured in $\mathrm{O}_{2}$-saturated $0.1 \mathrm{M} \mathrm{KOH}$ for $24 \mathrm{~h}$. As displayed in Figure 4i, the current intensity decay of PdFe PNHs is much lower than that of the commercial $\mathrm{Pt} / \mathrm{C}$ and $\mathrm{Pd}$ black during the entire time range. The PdFe PNHs still maintain $93.2 \%$ of original current density after tests, whereas the current losses of commercial $\mathrm{Pt} / \mathrm{C}$ and Pd black are $10.7 \%$ and $17.8 \%$ (inset of Figure 4i), respectively, implying that the PdFe PNHs have better stability as electrocatalysts of ORR. The outstanding ORR activity and stability of the PdFe PNHs can be put down to the unique porous, hydrangea-like morphology and alloyed components. Concretely, (i) the unique porous, hydrangea-like structure composed of interconnected small nanoparticles has a large surface area and abundant accessible active sites, which can boost mass diffusion and transport during the electrochemical course and eventually promote the reaction kinetics; (ii) the synergistic effects between $\mathrm{Pd}$ and $\mathrm{Fe}$ elements increase the efficient adsorption of active oxygen and migration of rival hydroxyl species on the surface of the PdFe PNHs, thus promoting the direct four-electron transfer and resulting in a superior ORR performance $[39,40]$.

\section{Conclusions}

In conclusion, we have presented a cyanogel-derived synthetic method for the fabrication of the porous PdFe nanohydrangeas. This strategy contains the formation of PdFe cyanogel and then chemical reduction with $\mathrm{N}_{2} \mathrm{H}_{4} \cdot \mathrm{H}_{2} \mathrm{O}$ solution. The as-synthesized PdFe alloys have unique porous, hydrangea-like structure composed of interconnected small nanoparticles. Because of the favorable structural advantages and synergistic effects between $\mathrm{Pd}$ and $\mathrm{Fe}$, the porous PdFe nanohydrangeas show excellent electrocatalytic activity and stability compared with the commercial Pd black and Pt/C catalysts with respect to ORR. This work offers a simple method for the development of Pd-based alloy nanocatalysts with porous structure which could advance the widespread applications of PEMFCs.

Supplementary Materials: The following are available online at https: / www.mdpi.com/article / 10.3390/nano11123382/s1, Equation S1: Formation equation of cyanogel from transition metal cyanometalates and tetrachlorometalates in aqueous solution, Figure S1: Digital photos showing the formation of PdFe cyanogel, Figure S2: FTIR spectra of (a) the $\mathrm{K}_{2} \mathrm{PdCl}_{4} / \mathrm{K}_{4} \mathrm{Fe}(\mathrm{CN})_{6}$ cyanogel and (b) pure $\mathrm{K}_{4} \mathrm{Fe}(\mathrm{CN})_{6}$, Figure S3: Typical SEM images of the porous PdFe nanohydrangeas at different magnifications, Figure S4: (a) STEM image and (b) EDX line scanning profile of the porous PdFe nanohydrangeas, Figure S5: XPS survey scan spectrum of the porous PdFe nanohydrangeas, Figure S6: (a) CV curves of the as-synthesized porous PdFe nanohydrangeas and commercial Pd black catalyst recorded in N2-purged $0.5 \mathrm{M} \mathrm{H} 2 \mathrm{SO} 4$ solution with a sweep rate of $50 \mathrm{mV} \mathrm{s}^{-1}$ and (b) Graphical comparison of the ECSA of the two catalysts, Figure S7: ORR polarization curves of the three catalysts obtained in $\mathrm{O} 2$-saturated $0.1 \mathrm{M} \mathrm{KOH}$ solution with a sweep rate of $5 \mathrm{mV}$ $\mathrm{s}^{-1}$ and different rotation speeds. (a) PdFe PNHs; (b) Commercial Pt/C; (c) Commercial Pd black. The relevant Koutecky-Levich plots at different potentials of the three catalysts. (d) PdFe PNHs; (e) Commercial Pt/C; (f) Commercial Pd black, Table S1: Comparison of the ORR activity of the porous PdFe nanohydrangeas with other electrocatalysts previously reported. References [41-48] were cited in Supplementary Materials.

Author Contributions: J.W., Z.L., X.Y. and P.C. designed and performed this research; J.W., Z.L. and X.Y. analyzed the data; Z.L. and C.Y. wrote and edited the manuscript. All authors have read and agreed to the published version of the manuscript.

Funding: This research was funded by the National Natural Science Foundation of China (22002053, 51873083) and the Natural Science Foundation of Jiangsu Province (BK20201004).

Data Availability Statement: Data are contained within the article. 
Conflicts of Interest: The authors declare no conflict of interest.

\section{References}

1. Liu, Q.T.; Liu, X.F.; Zheng, L.R.; Shui, J.L. The Solid-Phase Synthesis of an Fe-N-C Electrocatalyst for High-Power Proton-Exchange Membrane Fuel Cells. Angew. Chem. Int. Ed. 2018, 57, 1204-1208. [CrossRef]

2. Zeng, Y.C.; Shao, Z.G.; Zhang, H.J.; Wang, Z.Q.; Hong, S.J.; Yu, H.M.; Yi, B.L. Nanostructured ultrathin catalyst layer based on open-walled PtCo bimetallic nanotube arrays for proton exchange membrane fuel cells. Nano Energy 2017, 34, 344-355. [CrossRef]

3. Ren, H.; Wang, Y.; Yang, Y.; Tang, X.; Peng, Y.Q.; Peng, H.Q.; Xiao, L.; Lu, J.T.; Abruña, H.D.; Zhuang, L. Fe/N/C Nanotubes with Atomic Fe Sites: A Highly Active Cathode Catalyst for Alkaline Polymer Electrolyte Fuel Cells. ACS Catal. 2017, 7, 6485-6492. [CrossRef]

4. Liu, H.P.; Zhong, P.; Liu, K.; Han, L.; Zheng, H.Q.; Yin, Y.D.; Gao, C.B. Synthesis of ultrathin platinum nanoplates for enhanced oxygen reduction activity. Chem. Sci. 2018, 9, 398-404. [CrossRef]

5. Tao, Y.Y.; Liang, X.; Xu, G.C.; Li, D.W.; Li, Y.; Zhang, N.; Chen, Y.Z.; Jiang, X.F.; Gong, H.Y. Self-Supported Defect-Rich Au-Based Nanostructures as Robust Bifunctional Catalysts for the Methanol Oxidation Reaction and Oxygen Reduction Reaction in an Alkaline Medium. Nanomaterials 2021, 11, 2193. [CrossRef]

6. Chen, W.C.; Yang, G.; Zhao, Y.; Yuan, G.Q.; Ye, J.S.; Liu, H.Y.; Xiao, X.Y. Porous carbon polyhedrons with exclusive Metal-N moieties for efficient oxygen reduction reaction. Int. J. Hydrogen Energy 2021, 46, 39882-39891. [CrossRef]

7. He, B.H.; Chen, Y.Y.; Hu, D.; Wen, Z.Y.; Zhou, M.J.; Xu, W.Y. N-Doped hierarchical porous carbon nanoscrolls towards efficient oxygen reduction reaction in Zn-air batteries via interior and exterior modifications. Mater. Adv. 2021, 2, 7036-7044. [CrossRef]

8. Falco, G.; Florent, M.; Jagiello, J.; Cheng, Y.Q.; Daemen, L.L.; Ramirez-Cuesta, A.J.; Bandosz, T.J. Alternative view of oxygen reduction on porous carbon electrocatalysts: The substance of complex oxygen-surface interactions. Iscience 2021, $24,102216$. [CrossRef]

9. Han, M.N.; Shi, M.J.; Wang, J.; Zhang, M.L.; Yan, C.; Jiang, J.T.; Guo, S.H.; Sun, Z.Y.; Guo, Z.H. Efficient bifunctional Co/N dual-doped carbon electrocatalysts for oxygen reduction and evolution reaction. Carbon 2019, 153, 575-584. [CrossRef]

10. Li, Z.S.; Li, Y.Y.; He, C.Y.; Shen, P.K. Bimetallic PtAg alloyed nanoparticles and 3-D mesoporous graphene nanosheets hybrid architectures for advanced oxygen reduction reaction electrocatalysts. J. Mater. Chem. A 2017, 5, 23158-23169. [CrossRef]

11. Jiang, K.Z.; Zhao, D.D.; Guo, S.J.; Zhang, X.; Zhu, X.; Guo, J.; Lu, G.; Huang, X.Q. Efficient oxygen reduction catalysis by subnanometer Pt alloy nanowires. Sci. Adv. 2017, 3, e1601705. [CrossRef]

12. Pavlets, A.; Alekseenko, A.; Menshchikov, V.; Belenov, S.; Volochaev, V.; Pankov, I.; Safronenko, O.; Guterman, V. Influence of Electrochemical Pretreatment Conditions of PtCu/C Alloy Electrocatalyst on Its Activity. Nanomaterials 2021, 11, 1499. [CrossRef]

13. Liu, Z.Y.; Yang, X.Y.; Cui, L.R.; Shi, Z.P.; Lu, B.Q.; Guo, X.M.; Zhang, J.B.; Xu, L.; Tang, Y.W.; Xiang, Y. High-Performance Oxygen Reduction Electrocatalysis Enabled by 3D PdNi Nanocorals with Hierarchical Porosity. Part. Part. Syst. Charact. 2018, $35,1700366$. [CrossRef]

14. Liu, Z.Y.; Fu, G.T.; Li, J.H.; Liu, Z.Q.; Xu, L.; Sun, D.M.; Tang, Y.W. Facile synthesis based on novel carbon-supported cyanogel of structurally ordered $\mathrm{Pd}_{3} \mathrm{Fe} / \mathrm{C}$ as electrocatalyst for formic acid oxidation. Nano Res. 2018, 11, 4686-4696. [CrossRef]

15. Elsheikh, A.; McGregor, J. Synthesis and Characterization of PdAgNi/C Trimetallic Nanoparticles for Ethanol Electrooxidation. Nanomaterials 2021, 11, 2244. [CrossRef] [PubMed]

16. Liu, Y.C.; Jiang, J.T.; Yuan, Y.Y.; Jiang, Q.L.; Yan, C. Vertically Aligned $\mathrm{NiCo}_{2} \mathrm{O}_{4}$ Nanosheet-Encapsulated Carbon Fibers as a Self-Supported Electrode for Superior $\mathrm{Li}^{+}$Storage Performance. Nanomaterials 2019, 9, 1336. [CrossRef]

17. Goswami, C.; Saikia, H.; Tada, K.; Tanaka, S.; Sudarsanam, P.; Bhargava, S.K.; Bharali, P. Bimetallic Palladium-Nickel Nanoparticles Anchored on Carbon as High-Performance Electrocatalysts for Oxygen Reduction and Formic Acid Oxidation Reactions. ACS Appl. Energy Mater. 2020, 3, 9285-9295. [CrossRef]

18. $\mathrm{Wu}, \mathrm{D} . \mathrm{F}$; Cheng, D.J. Structure-controlled synthesis of one-dimensional PdCu nanoscatalysts via a seed-mediated approach for oxygen reduction reaction. Appl. Surf. Sci. 2019, 493, 139-145. [CrossRef]

19. Li, X.; Li, X.X.; Liu, C.X.; Huang, H.W.; Gao, P.F.; Ahmad, F.; Luo, L.H.; Ye, Y.F.; Geng, Z.G.; Wang, G.X.; et al. Atomic-Level Construction of Tensile-Strained PdFe Alloy Surface toward Highly Efficient Oxygen Reduction Electrocatalysis. Nano Lett. 2020, 20, 1403-1409. [CrossRef] [PubMed]

20. Kang, Y.S.; Choi, D.; Cho, J.; Park, H.Y.; Lee, K.S.; Ahn, M.; Jang, I.; Park, T.; Ham, H.C.; Yoo, S.J. Highly Active and Durable Ordered Intermetallic PdFe Electrocatalyst for Formic Acid Electrooxidation Reaction. ACS Appl. Energy Mater. 2020, 3, $4226-4237$. [CrossRef]

21. Yang, S.W.; Chung, Y.J.; Lee, K.S.; Kwon, Y.C. Enhancements in catalytic activity and duration of PdFe bimetallic catalysts and their use in direct formic acid fuel cells. J. Ind. Eng. Chem. 2020, 90, 351-357. [CrossRef]

22. Douk, A.S.; Farsadrooh, M.; Damanigol, F.; Moghaddam, A.A.; Saravani, H.; Noroozifar, M. Porous three-dimensional network of Pd-Cu aerogel toward formic acid oxidation. RSC Adv. 2018, 8, 23539-23545. [CrossRef]

23. Xu, H.; Shang, H.Y.; Wang, C.; Jin, L.J.; Chen, C.Y.; Du, Y.K. Nanoscale engineering of porous Fe-doped Pd nanosheet assemblies for efficient methanol and ethanol electrocatalyses. Nanoscale 2020, 12, 2126-2132. [CrossRef]

24. Wang, Y.Y.; Xie, C.; Liu, D.D.; Huang, X.B.; Huo, J.; Wang, S.Y. Nanoparticles-Stacked Porous Nickel-Iron Nitride Nanosheet: A Highly Efficient Bifunctional Electrocatalyst for Overall Water Splitting. ACS Appl. Mater. Interfaces 2016, 8, 18652-18657. [CrossRef] 
25. Qin, Q.; Xie, J.; Dong, Q.Z.; Yu, G.; Chen, H. Surfactant-free fabrication of porous PdSn alloy networks by self-assembly as superior freestanding electrocatalysts for formic acid oxidation. N. J. Chem. 2019, 43, 19242-19252. [CrossRef]

26. Mattarozzi, L.; Cattarin, S.; Comisso, N.; Gerbasi, R.; Guerriero, P.; Musiani, M.; Verlato, E. Electrodeposition of compact and porous $\mathrm{Cu}-\mathrm{Pd}$ alloy layers and their application to nitrate reduction in alkali. Electrochim. Acta 2017, 230, 365-372. [CrossRef]

27. Mattarozzi, L.; Cattarin, S.; Comisso, N.; Gerbasi, R.; Guerriero, P.; Musiani, M.; Vázquez-Gómez, L. Preparation of compact and porous Pd-Ni alloys and study of their performances for ethanol oxidation in alkali. Electrochim. Acta 2019, 307, 503-511. [CrossRef]

28. Sheng, J.L.; Kang, J.H.; Ye, H.Q.; Xie, J.Q.; Zhao, B.; Fu, X.Z.; Yu, Y.; Sun, R.; Wong, C.P. Porous octahedral PdCu nanocages as highly efficient electrocatalysts for the methanol oxidation reaction. J. Mater. Chem. A 2018, 6, 3906-3912. [CrossRef]

29. Guo, J.C.; Gao, L.; Tan, X.; Yuan, Y.L.; Kim, J.; Wang, Y.; Wang, H.; Zeng, Y.J.; Choi, S.I.; Smith, S.C.; et al. Template-Directed Rapid Synthesis of Pd-Based Ultrathin Porous Intermetallic Nanosheets for Efficient Oxygen Reduction. Angew. Chem. Int. Ed. 2021, 60, 10942-10949. [CrossRef] [PubMed]

30. Pfennig, B.W.; Bocarsly, A.B.; Prud'homme, R.K. Synthesis of a novel hydrogel based on a coordinate covalent polymer network. J. Am. Chem. Soc. 1993, 115, 2661-2665. [CrossRef]

31. Heibel, M.; Kumar, G.; Wyse, C.; Bukovec, P.; Bocarsly, A.B. Use of sol-gel chemistry for the preparation of cyanogels as ceramic and alloy precursors. Chem. Mater. 1996, 8, 1504-1511. [CrossRef]

32. Vondrova, M.; McQueen, T.M.; Burgess, C.M.; Ho, D.M.; Bocarsly, A.B. Autoreduction of Pd-Co and Pt-Co cyanogels: Exploration of cyanometalate coordination chemistry at elevated temperatures. J. Am. Chem. Soc. 2008, 130, 5563-5572. [CrossRef]

33. Peng, X.W.; Ye, W.; Ding, Y.C.; Jiang, S.H.; Hanif, M.; Liao, X.J.; Hou, H.Q. Facile synthesis, characterization and application of highly active palladium nano-network structures supported on electrospun carbon nanofibers. RSC Adv. 2014, 4, 42732-42736. [CrossRef]

34. Su, Y.H.; Jiang, H.L.; Zhu, Y.H.; Yang, X.L.; Shen, J.H.; Zou, W.J.; Chen, J.D.; Li, C.Z. Enriched graphitic N-doped carbon-supported $\mathrm{Fe}_{3} \mathrm{O}_{4}$ nanoparticles as efficient electrocatalysts for oxygen reduction reaction. J. Mater. Chem. A 2014, 2, 7281-7287. [CrossRef]

35. Lin, L.; Zhu, Q.; Xu, A.W. Noble-Metal-Free Fe-N/C Catalyst for Highly Efficient Oxygen Reduction Reaction under Both Alkaline and Acidic Conditions. J. Am. Chem. Soc. 2014, 136, 11027-11033. [CrossRef]

36. Kong, A.G.; Zhu, X.F.; Han, Z.; Yu, Y.Y.; Zhang, Y.B.; Dong, B.; Shan, Y.K. Ordered Hierarchically Micro- and Mesoporous $\mathrm{Fe}-\mathrm{N}_{\mathrm{x}}$-Embedded Graphitic Architectures as Efficient Electrocatalysts for Oxygen Reduction Reaction. ACS Catal. 2014, 4, 1793-1800. [CrossRef]

37. Hu, S.; Munoz, F.; Noborikawa, J.; Haan, J.; Scudiero, L.; Ha, S. Carbon supported Pd-based bimetallic and trimetallic catalyst for formic acid electrochemical oxidation. Appl. Catal. B Environ. 2016, 180, 758-765. [CrossRef]

38. Zhang, L.; Wan, L.; Ma, Y.R.; Chen, Y.; Zhou, Y.M.; Tang, Y.W.; Lu, T.H. Crystalline palladium-cobalt alloy nanoassemblies with enhanced activity and stability for the formic acid oxidation reaction. Appl. Catal. B Environ. 2013, 138, 229-235. [CrossRef]

39. Xu, C.X.; Liu, Y.Q.; Hao, Q.; Duan, H.M. Nanoporous PdNi alloys as highly active and methanol-tolerant electrocatalysts towards oxygen reduction reaction. J. Mater. Chem. A 2013, 1, 13542-13548. [CrossRef]

40. Jiang, G.M.; Zhu, H.Y.; Zhang, X.; Shen, B.; Wu, L.H.; Zhang, S.; Lu, G.; Wu, Z.B.; Sun, S.H. Core/Shell Face-Centered Tetragonal FePd/Pd Nanoparticles as an Efficient Non-Pt Catalyst for the Oxygen Reduction Reaction. ACS Nano 2015, 9, 11014-11022. [CrossRef] [PubMed]

41. Liu, S.L.; Mu, X.Q.; Duan, H.Y.; Chen, C.Y.; Zhang, H. Pd Nanoparticle Assemblies as Efficient Catalysts for the Hydrogen Evolution and Oxygen Reduction Reactions. Eur. J. Inorg. Chem. 2017, 2017, 535-539. [CrossRef]

42. Zhong, X.; Qin, Y.Y.; Chen, X.L.; Xu, W.L.; Zhuang, G.; Li, X.N.; Wang, J.G. PtPd alloy embedded in nitrogen-rich graphene nanopores: High-performance bifunctional electrocatalysts for hydrogen evolution and oxygen reduction. Carbon 2017, 114, 740-748. [CrossRef]

43. Goswami, C.; Saikia, H.; Jyoti Borah, B.; Jyoti Kalita, M.; Tada, K.; Tanaka, S.; Bharali, P. Boosting the electrocatalytic activity of $\mathrm{Pd} / \mathrm{C}$ by Cu alloying: Insight on Pd/Cu composition and reaction pathway. J. Colloid Interface Sci. 2021, 587, 446-456. [CrossRef]

44. Yang, H.Y.; Wang, K.; Tang, Z.H.; Liu, Z.; Chen, S.W. Bimetallic PdZn nanoparticles for oxygen reduction reaction in alkaline medium: The effects of surface structure. J. Catal. 2020, 382, 181-191. [CrossRef]

45. Thi, M.L.N.; Tran, T.H.; Anh, P.D.H.; Nhac-Vu, H.T.; Bui, Q.B. An innovative catalyst of nickel-palladium alloy nanocrystals embedded nitrogen-doped graphene for efficient oxygen reduction reaction. J. Alloys Compd 2019, 797, 314-324. [CrossRef]

46. Lu, Y.N.; Zhao, S.L.; Yang, R.; Xu, D.D.; Yang, J.; Lin, Y.; Shi, N.E.; Dai, Z.H.; Bao, J.C.; Han, M. Well-Coupled Nanohybrids Obtained by Component-Controlled Synthesis and in Situ Integration of $\mathrm{Mn}_{\mathrm{x}} \mathrm{Pd}_{\mathrm{y}}$ Nanocrystals on Vulcan Carbon for Electrocatalytic Oxygen Reduction. ACS Appl. Mater. Interfaces 2018, 10, 8155-8164. [CrossRef] [PubMed]

47. Liu, S.L.; Zhang, Q.H.; Li, Y.F.; Han, M.; Gu, L.; Nan, C.W.; Bao, J.C.; Dai, Z.H. Five-Fold Twinned Pd 2 NiAg Nanocrystals with Increased Surface Ni Site Availability to Improve Oxygen Reduction Activity. J. Am. Chem. Soc. 2015, 137, 2820-2823. [CrossRef]

48. Xue, H.R.; Tang, J.; Gong, H.; Guo, H.; Fan, X.L.; Wang, T.; He, J.P.; Yamauchi, Y. Fabrication of PdCo Bimetallic Nanoparticles Anchored on Three-Dimensional Ordered N-Doped Porous Carbon as an Efficient Catalyst for Oxygen Reduction Reaction. ACS Appl. Mater. Interfaces 2016, 8, 20766-20771. [CrossRef] [PubMed] 